\title{
Pierre Gentelle, 1999, Chine et « Chinois » outre mer à
} l'orée du 21e siècle

Paris, SEDES, $312 \mathrm{p}$.

\section{Céline Claude}

\section{OpenEdition}

\section{Journals}

Édition électronique

URL : http://journals.openedition.org/rge/4262

DOI : $10.4000 /$ rge. 4262

ISSN : 2108-6478

\section{Éditeur}

Association des géographes de l'Est

Édition imprimée

Date de publication : 1 janvier 2000

ISSN : 0035-3213

\section{Référence électronique}

Céline Claude, "Pierre Gentelle, 1999, Chine et «Chinois » outre mer à l'orée du 21e siècle », Revue Géographique de l'Est [En ligne], vol. 40 / 1-2 | 2000, mis en ligne le 07 août 2013, consulté le 25 septembre 2020. URL : http://journals.openedition.org/rge/4262 ; DOI : https://doi.org/10.4000/rge. 4262

Ce document a été généré automatiquement le 25 septembre 2020

Tous droits réservés 


\section{Pierre Gentelle, 1999, Chine et «Chinois » outre mer à l'orée du $21 e$ siècle}

Paris, SEDES, 312 p.

\section{Céline Claude}

\section{RÉFÉRENCE}

Pierre Gentelle, 1999, Chine et « Chinois » outre mer à l'orée du 21e siècle, Paris, SEDES, 312

p.

1 Cet ouvrage est composé de 4 grandes parties :

- La première partie s'intitule : « la Chine et la mondialisation ». Elle aborde la Chine par des biais historiques, sociaux, juridiques, ...

3 Le dernier chapitre évoque plus particulièrement "les Chinois » outre-mer: une justification du titre et du vocabulaire, et une présentation succincte des caractères de l'émigration chinoise sont développées ici.

4 - La seconde partie : "La Chine dans son territoire " étudie quelques aspects des relations entre la société et son espace (perception et pratique des lieux, quelques grands flux, métropole/campagne).

- La troisième partie est l'étude de la Chine à l'échelle régionale.

6 L'auteur, après avoir évoqué les problèmes de la régionalisation, étudie de manière inégale les régions suivantes :

- La Chine du Nord (Hebei, Shandong, Henan et les « capitales » : Pékin et Tianjin). Puis, il développe à une échelle plus fine le cas de Pékin.

- Shanghai et l'axe du Yangziang (c'est-à-dire les provinces : Jiangsu, Zhejiang, Anhui, Jiangxi, Hubei, Hunan, Sichuan, Chongqing)

- La Chine du lœss : Shanxi et Shaanxi 
- «Karst, riz, mousson », espace qui correspond au Guangxi, Guizhou et Yunnan.

- « La Chine "bleue" du Sud Est », c'est-à-dire Fujian, Hainan, Guangdong.

- «L'eau, les fleuves, les lacs» : Xinjiang, Mongolie en quelques lignes et Tibet.

7 Mais certaines provinces ne sont pas clairement évoquées; il n'y a pas de développement particulier pour: Gansu, Qinghai, Ningxia, et, surtout, le Nord-Est chinois (Mandchourie) n'est pas du tout présenté dans cette étude régionale; or, il s'agit d'un espace capital à l'échelle chinoise : est-ce un oubli ?!

- La quatrième partie est une présentation complète et claire de Taiwan, dont l'auteur est A. Gamblin (qui a effectué plusieurs travaux sur la question), présentation qui s'appuie sur des statistiques, des documents, des éclairages très nouveaux.

Elle met en lumière les incertitudes, les handicaps et les innovations, les réussites les plus récentes de Taiwan (ce n'est pas le cas pour Hong Kong et Macao, non présentés dans ces études régionales)

10 Cet ouvrage pâtit donc d'une rédaction hâtive (oubli de la Mandchourie, certaines cartes n'ont pas d'échelle, quelques erreurs ont pu se glisser dans le texte), mais il a l'avantage de présenter des problématiques pertinentes et «nouvelles », qui incitent à la réflexion.

11 Un autre point fort de cet ouvrage sont les nombreux documents (51) présentant les statistiques les plus récentes et qui sont surtout très souvent exploités, commentés brièvement et clairement sur la page voisine. La plupart de ces documents sont, d'ailleurs, inédits.

12 Un autre outil pédagogique intéressant correspond au découpage en paragraphes courts, introduits par un titre succinct en gras. Ceci permet, en effet, une lecture cursive.

\section{AUTEURS}

\section{CÉLINE CLAUDE}

Université de Nancy 2 